\title{
Investigation on Static Electrification Phenomenon of Ester Liquids and Mineral oil
}

\author{
A. Beroual ${ }^{* 1}$, F. Sadaoui ${ }^{1}$ M-L. Coulibaly ${ }^{2}$ and C. Perrier ${ }^{2,3}$ \\ ${ }^{1}$ Ecole Centrale de Lyon, University of Lyon, Ampere CNRS UMR 5005, \\ 36 avenue Guy de Collongue, 69134 Ecully, France \\ ${ }^{2}$ Alstom Grid, TICC Research Center, 129, avenue de Paris, 91300 Massy, France \\ ${ }^{3}$ Alstom Grid, ARC Research Center, 130, rue Léon Blum, 69611 Villeurbanne, France \\ *corresponding author, e-mail: Abderrahmane.Beroual@ec-lyon.fr
}

\begin{abstract}
This paper aims at the comparison of the Electrostatic Charging Tendency (ECT) of mineral, vegetable and synthetic oils using a spinning disk system (CIGRE Cell) covered on its both sides with different types of pressboards and papers. The ECT of insulating oils generated by the charge concentration gradient at the oil - pressboard/paper interfaces are analyzed in function of the rotating speed of the disk. It is shown that the generated charge is slightly higher with vegetable oil than that with mineral and synthetic ester oils. This may be due to differences in the molecular structures of these oils, whose interaction with the pressboard/paper is different; the phenomena occurring at the double-layer (interface) are not identical. However, the differences observed do not constitute an obstacle to the use of vegetable oil as a substitute for mineral or synthetic oils, with respect to the problems and risks associated with static electrification phenomena.
\end{abstract}

Keywords- Electrostatic Charging Tendency (ECT), natural and synthetic ester oils, mineral oil, spinning disk system.

\section{INTRODUCTION}

Due the increasing demand for the use of environmental friendly products, manufacturers are invited to use more and more vegetable oils (natural esters) to fill transformers. Natural esters are biodegradable, non-toxic and renewable since they can be extracted from vegetables; they have better fire safety characteristics since their flash and fire points are higher than those of mineral oils and they present lower aquatic or earth danger than conventional mineral oils.

Beside criteria vegetable oils have to satisfy (stability oxidation, viscosity and heat transfer ...), one has to drive research on the behaviour of these natural oils with respect to static electrification concern. The phenomenon of static electrification resulting of flowing oil through the insulated cooling ducts in power transformers constitutes currently a major care for manufacturers and users. This is in relation with the numerous failures of power transformers, reported through the world and attributed to this phenomenon in 1970' years and later. Many studies have been dedicated to the electrostatic charging tendency (ECT) of mineral oil and measurement of the leakage current generated by the charge concentration gradient at the oil/pressboard interface versus many parameters (nature of the pressboard, temperature, ageing, streaming rate (speed) ...), using different test cells, to understand this phenomenon. Some studies have been also conducted with natural ester oils on the charge generation using ministatic charge tester and the charge accumulation resulting of oil circulation in a test loop [5].

This paper is devoted to the analysis of the Electrostatic Charging Tendency (ECT) of mineral, vegetable and synthetic oils using a spinning disk system (CIGRE Cell) covered on its both sides with a given pressboard/paper. The (ECT) of insulating oils generated by the charge concentration gradient at the oil-pressboard/paper interface are analyzed in function of rotating speed of the disk.

\section{EXPERIMENTS}

The experiments were achieved using a CIGRE test cell [1] consisting of a spinning metallic disk covered on both sides with different pressboards and papers immersed in a tank filled with the test oil (Figure 1). The disk can be moved thanks to small DC motor. This type of cell can operate at high rotational speeds inducing turbulent flow of liquid; in our investigation, the rotating velocity of the disk was varied between 100 to $700 \mathrm{rpm}$ (round per minute). This device is considered as a good simulator of real hydrodynamic conditions in power transformers. The metallic disk of $150 \mathrm{~mm}$ diameter and $7.5 \mathrm{~mm}$ thick is placed in the center of the tank $170 \mathrm{~mm}$ in inner diameter and $120 \mathrm{~mm}$ in height where it is driven at variable speed. This system (tank and rotating disk) are made of aluminum alloy (duralumin). The static electrification current (leakage current) generated by the rotating motion of the disk in oil and drained toward the tank wall where they are collected, was measured (in pA) thanks to an electrometer (Keithley Model 6517 A) inserted between the tank and the earth. The data were then collected and processed using a PC, and the LabVIEW $^{\mathrm{TM}}$ application software.

Three types of new oils are used namely mineral oil (MO), vegetable oil (VO) and synthetic ester oil (SO). Their water content is measured before the test through a coulometer Metler Toledo DL32 KF type (Table 1. 1).

The solid insulating are two types of papers (Kraft and $\mathrm{TU})$ and three types of pressboards ( $\mathrm{H}, \mathrm{X}$ and $\mathrm{KP}$ ) of $2 \mathrm{~mm}$ thickness that are pre-compressed pressboards of type B3.1 $\left(\varepsilon_{\mathrm{r}}=4\right)$ used in power transformers and two types of papers (Kraft and TU), dried and impregnated with all three oils. Before impregnation, the pressboards and papers were dried at $85{ }^{\circ} \mathrm{C}$ in a vacuum oven for 120 hours under a pressure of about $0.1 \mathrm{kPa}$. Then the samples were impregnated under 
vacuum with treated oil preheated at $80{ }^{\circ} \mathrm{C}$. After the drying process and impregnating, the water content of pressboard is of about $0.5 \%$.

Table 1. Characteristics of tested oils; $\varepsilon_{r}$ is the dielectric constant.

\begin{tabular}{|c|c|c|c|c|}
\hline Oils & $\begin{array}{c}\text { Relative } \\
\text { Water } \\
\text { Content } \\
(\%)\end{array}$ & $\varepsilon_{r}$ & $\begin{array}{c}\text { Tan } \delta \\
\text { at } 90^{\circ} \mathrm{C}\end{array}$ & $\begin{array}{c}\text { Acidity } \\
\text { index } \\
(\mathrm{mgKOH} / \mathrm{g})\end{array}$ \\
\hline $\mathrm{MO}$ & $\sim 9$ & 2.2 & $<0.005$ & $<0.01$ \\
\hline $\mathrm{VO}$ & $\sim 5$ & 3.2 & $<0.05$ & $<0.06$ \\
\hline $\mathrm{SO}$ & $\sim 2$ & 3 & $<0.03$ & $<0.07$ \\
\hline
\end{tabular}

The measurements of electrostatic charge tendency (ECT) were performed on different couples pressboard (or paper) / oil with combinations of the three types of oils. For each pressboard (or paper) / oil couple, the evolution of the charge for a period of 1 hour is performed for different rotation speeds of the spinning disk $(100,200,400,600$ and $700 \mathrm{rpm})$.

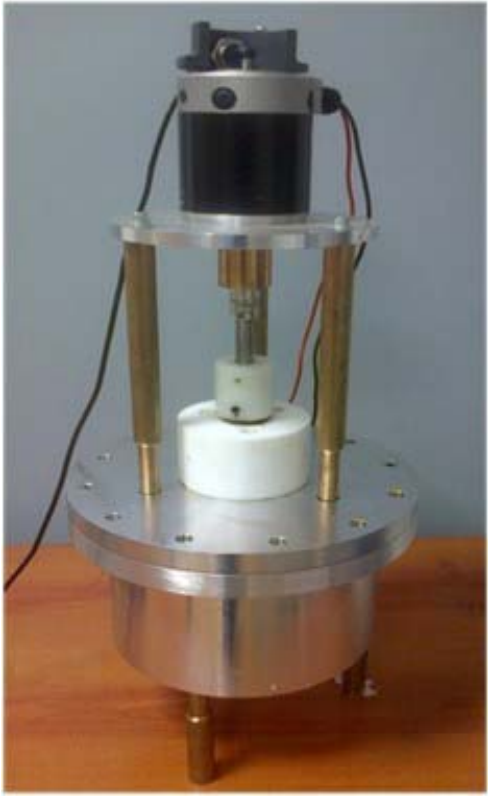

(a)

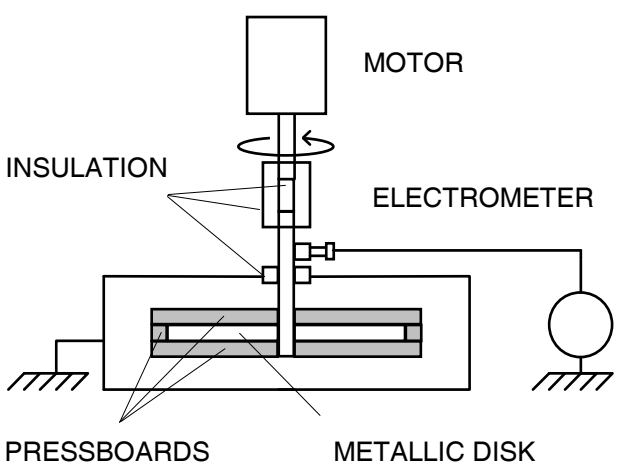

(b)

Figure 1: General view of spinning disk test cell (CIGRE test cell) (a) and its diagram (b)
III.

EXPERIMENTAL RESULTS

The leakage current and thus ECT increase with the rotational speed of the disk and/or the accumulation time whatever the solid sample (paper or pressboard) and oil. Similar results have been reported elsewhere [2-3]. Figures 2 to 4 depict some examples for different papers in the three oils.

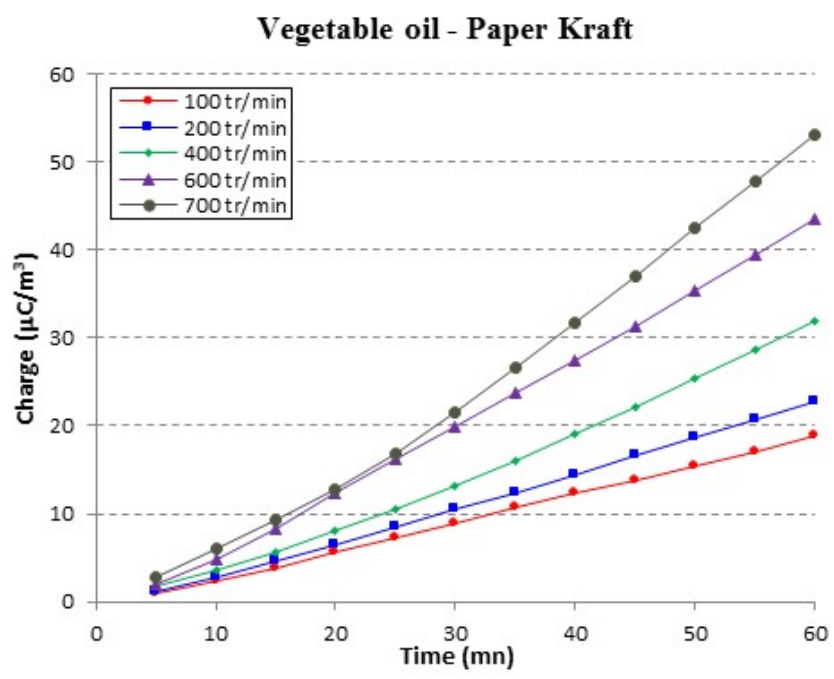

Vegetable oil - Paper TU

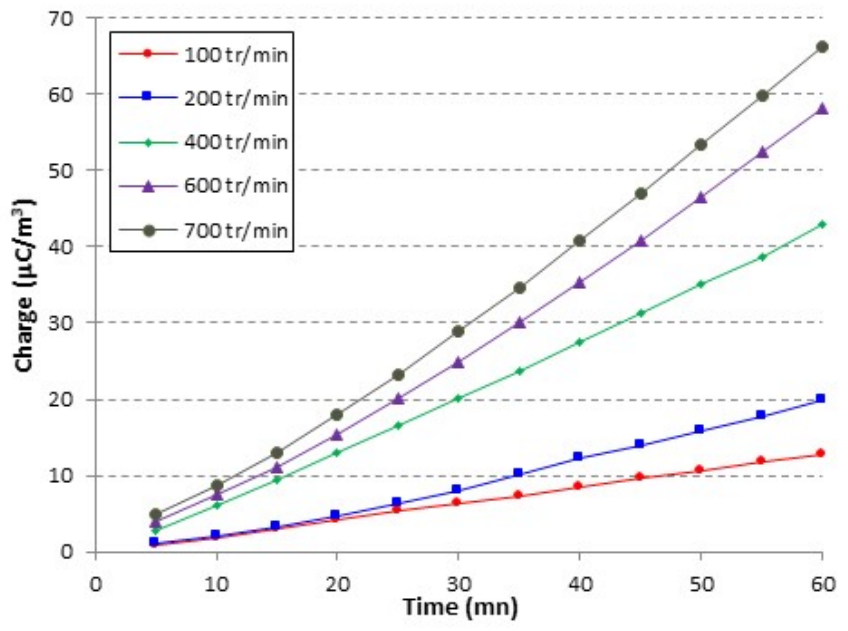

Figure 2. The temporal evolution of the electrostatic charging tendency (ECT) for vegetable oil for different spinning disk velocity performed at ambient $\left(20^{\circ} \mathrm{C}\right)$. Disk covered with different types of papers: TU and Kraft.

Figure 5 shows a comparison between the three oils (vegetable, mineral and synthetic) for each type of paper. We observe that, whatever the type of paper, the ECT generated in vegetable oil is the most important confirming the literature data [5]. Nevetheless, attention must be paid on the fact that only charge generation is measured in this study. Other studies on charge accumulation [5] have shown that risk is limited. Mineral oil is the one that produces the least ECT with both papers (Kraft and TU). With Kraft paper, the ECT measured with vegetable oil is greater than that with mineral and synthetic oils whatever the rotating speed while with TU paper this is not the case that from 400 rpm; for low speeds, the values of ECT are similar. 


\section{Synthetic oil- Paper Kraft}

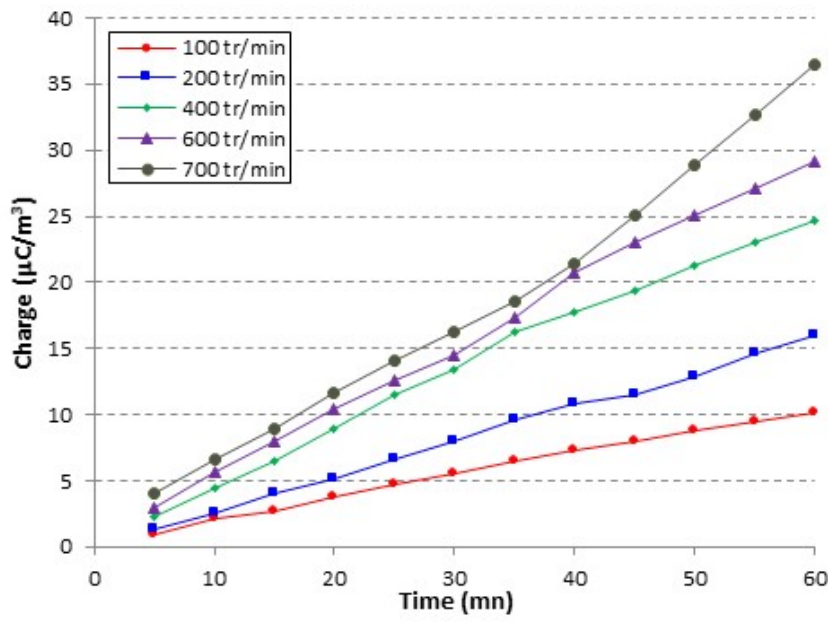

Synthetic oil- Paper TU

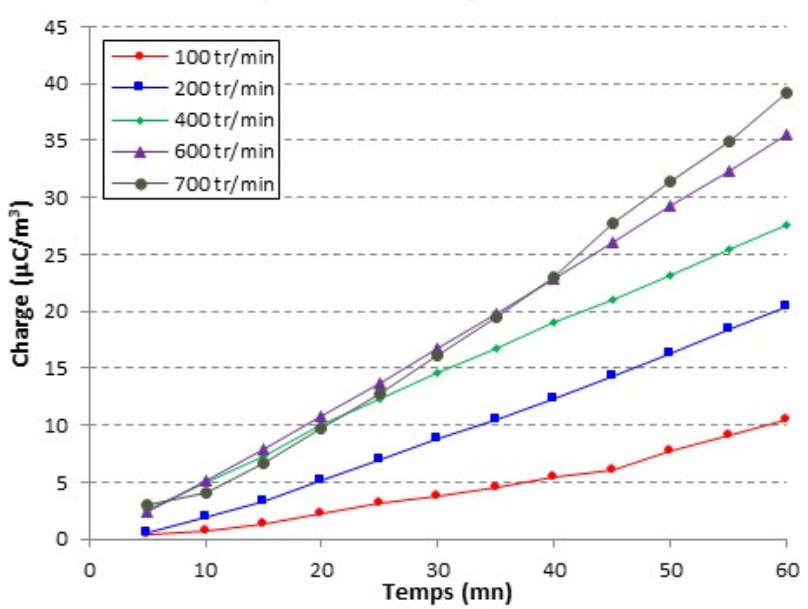

Figure 3. The temporal evolution of the electrostatic charging tendency (ECT) for synthetic ester oil for different spinning disk velocity performed at ambient $\left(20^{\circ} \mathrm{C}\right)$. Disk covered with different types of papers: TU and Kraft.

\section{Mineral oil - Paper Kraft}

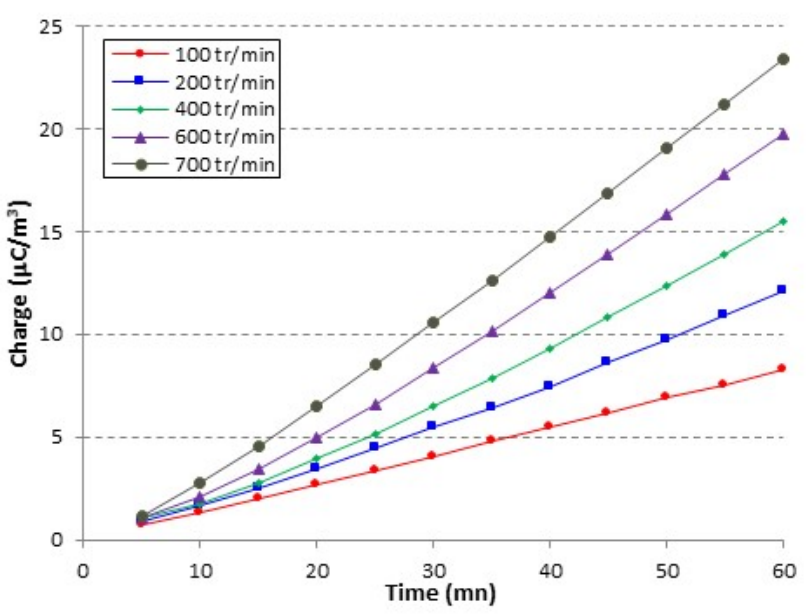

The comparison of the trend of ECT between the different types of pressboards and papers for given oil is shown in Figure 6.

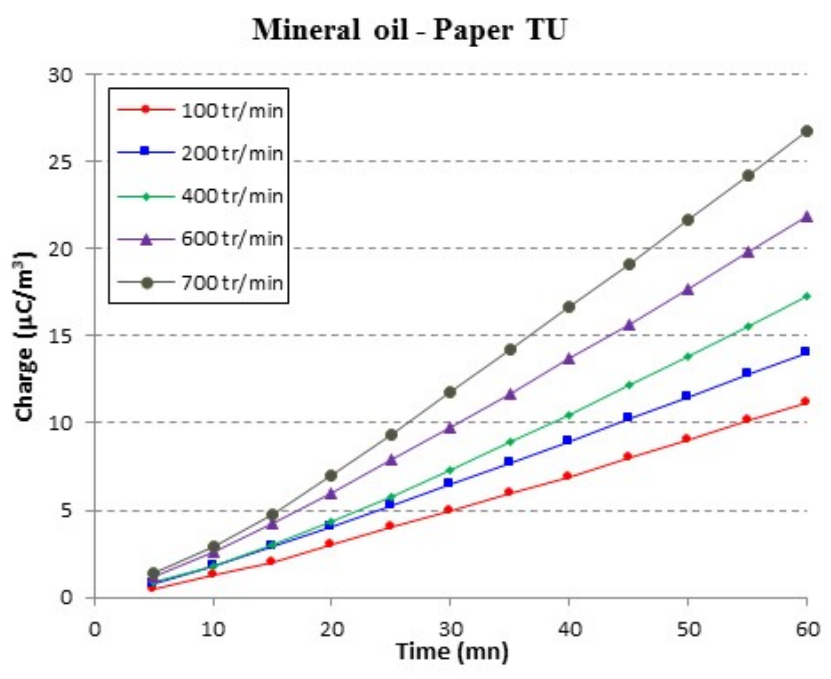

Figure 4. The temporal evolution of the electrostatic charging tendency (ECT) for mineral oil for different spinning disk velocity performed at ambient $\left(20^{\circ} \mathrm{C}\right)$. Disk covered with different types of papers: TU and Kraft.

\section{Paper Kraft}

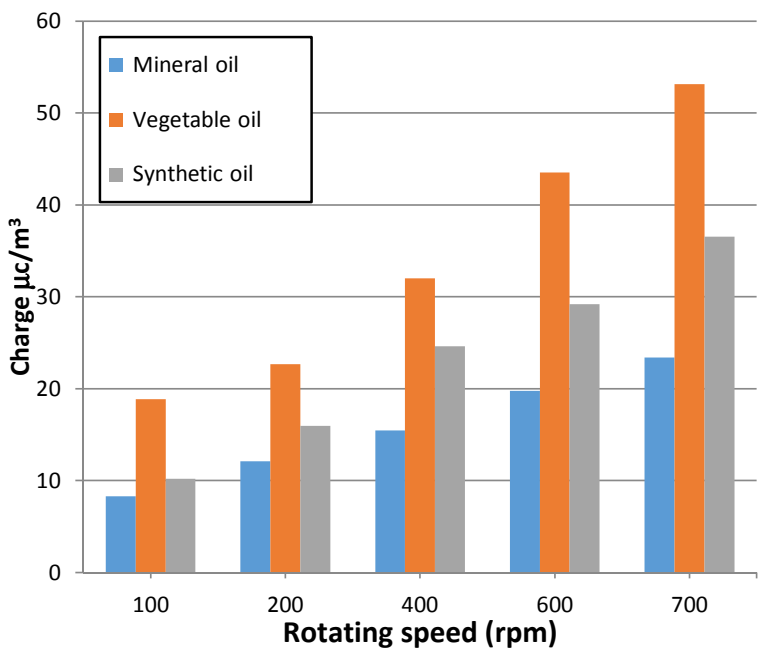

Paper TU

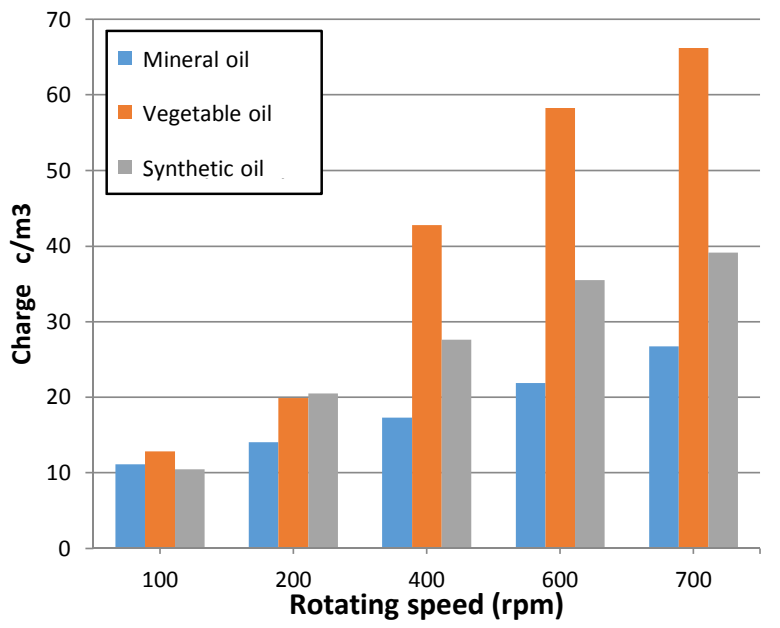

Figure 5. Comparison of the electrostatic charging tendency (ECT) of the three types of oils versus the spinning disk velocity for each type of papers. 


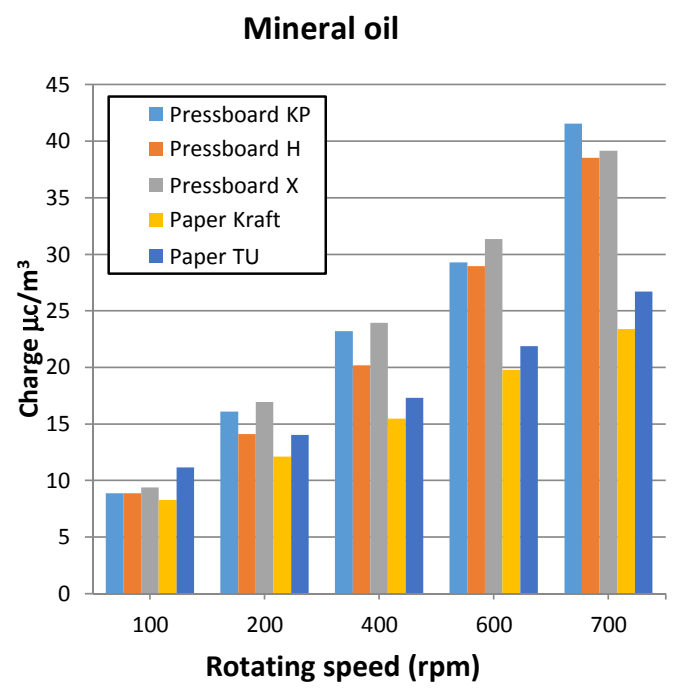

Synyhetic oil

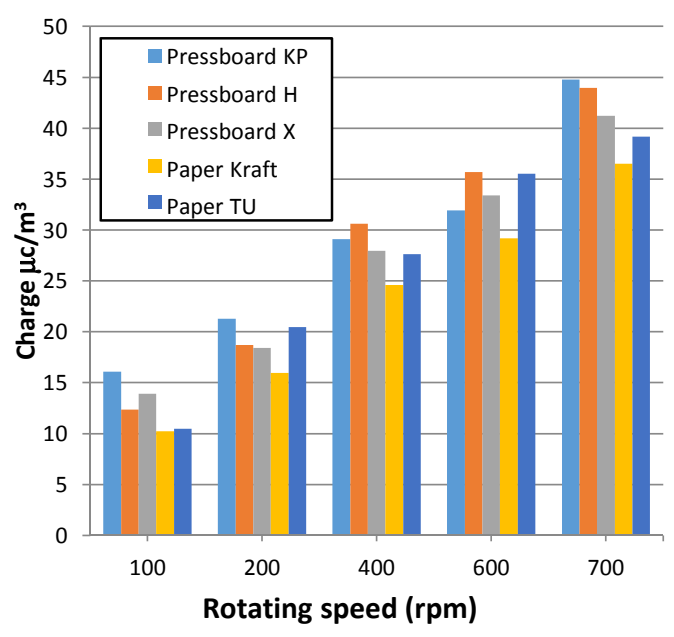

Vegetable oil

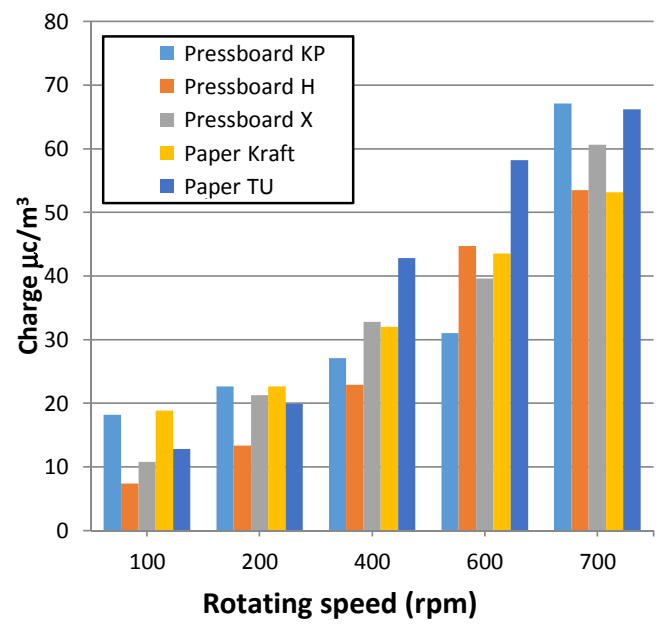

Figure 6. Comparison of the electrostatic charging tendency (ECT) for each type of oil versus the spinning disk velocity and a disk covered with the different types of pressboards and papers.
We observe that with mineral oil, Kraft and TU papers tend to create less charges when the rotational speed increases, while with synthetic and vegetable oils, the measured charges are of the same order with different types of pressboards and papers especially when increasing the rotating speed of the disk ( $\geq 400 \mathrm{rpm})$. These differences are likely due to chemical reactions at the oil - pressboard/paper interfaces [4] that depend on the physicochemical composition of both solid materials and oils [2 - 4]. On the other hand and as showed in previous work [2, 3], the roughness of pressboard (or paper) and water content in both solid insulating and oil influence the ECT; the ECT increases with the roughness and water content. It is the same with the conductivity of ester oils which is much higher than that of mineral oils (about two orders of magnitudes): the higher the oil electrical conductivity, the higher the ECT is $[2,3]$. The viscosity of oil may also play a role in the mechanism of charge generation; the viscosity of vegetable oil is much higher than that of synthetic ester and mineral oil.

\section{CONCLUSION}

This work shows that the generated electrostatic charge is generally higher with vegetable oil with the different pressboards and papers.

Mineral oil is the one that produces the least amount of electrostatic charges with both papers (Kraft and TU). The ECT measured with the Kraft paper/vegetable oil couple is greater than that of Kraft paper/mineral oil and Kraft paper /synthetic oil, whatever the rotating speed while with TU paper, this is observed only for speeds higher than $400 \mathrm{rpm}$; for low speeds the electrostatic charges (ECT) are similar.

The fact that ECT with vegetable oil is larger than with the other two oils (mineral and synthetic ester) may be due to the differences in the molecular structures of these oils, whose interaction with pressboard and paper is different; the phenomena occurring at the double-layer (interface) are not identical. The observed differences do not constitute an obstacle to the use of vegetable oil as a substitute for mineral or synthetic oils, with respect to the problems and risks associated with static electrification phenomena.

\section{REFERENCES}

[1] CIGRE brochure $\mathrm{N}^{\circ} 170$ : "Static electrification in power transformers", Joint WG 12/15.13, August 2000

[2] L. Peyraque, A. Beroual, C. Boidon and F. Buret, Static Electrification and Partial Discharges Induced by Oil Flow in Power Transformers, IEEE Trans. Dielectrics and Electr. Insul., Vol. 2, $\mathrm{n}^{\circ} 1$, pp. 40-45, 1995.

[3] L. Peyraque, A. Beroual and F. Buret, Static Electrification of Pressboard/Oil Interface and Transients Phenomena, IEEE Trans. Dielectrics and Electrical Insulation, Vol. 5, No.3, 1998, pp. 443-449.

[4] T. Paillat, L. Onic, O. Moreau, Y. Bertrand, G. Mortha, N. Charvet and G. Touchard, "Influence of Pressboard hysicochemical Composition on Static Electrification in Power Transformers", IEEE Trans. on Industry Applications, Vol. 39, pp. 346-354, 2003.

[5] T. Paillat, Y. Zelu, G. Morin, C. Perrier, "Ester oils and flow electrification hazards in power transformers", IEEE TDEI, Vol. 19, $\mathrm{n}^{\circ} 5$, 